\section{Taking Stock of Your Institution's Marketing Efforts}

\section{Erin Shea}

Erin Shea is Supervisor of the Harry Bennett and Weed Memorial and Hollander branches of the Ferguson Library in Stamford, Connecticut. Previously, she managed over 400 programs annually, including author events, film screenings, computer classes, music concerts, hands-on workshops, and more as the Head of Adult Programming at Darien Library in Darien, Connecticut. She is a memoir columnist for Library Journal and a 2014 Library Journal Mover and Shaker. You can follow her on twitter (@erintheshea).

Correspondence concerning this column should be directed to Nicole Eva and Erin Shea, email: nicole.eva@uleth .ca and eshea@fergusonlibrary.org.
Just as librarians weed their collections to make sure materials are relevant, up-to-date, and in good condition, they should also weed their marketing efforts. The first step is to take stock of marketing plans both physical and digital, and the second step is to decide which efforts command more time and which deserve less. This article introduces librarians to the process of taking stock of a marketing plan.-Editors

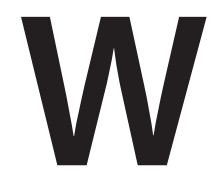
hether it's through the use of a vendor's services or the hard work of pages and volunteers, library staff regularly take stock of their collections. They have to make sure that whatever their ILS says is on the shelf is indeed on that shelf, replace items that have circulated dozens of times, and weed items that haven't gone out in years. This due diligence can also be applied to a library's marketing efforts. With the everchanging ways users receive and share information, it makes sense to check in regularly to see which marketing efforts are still working and which have blended into the scenery of information users receive each day. It's also a good opportunity to look at the way similar institutions market their programs and services and muse over whether those tactics could also work for yours.

The Merriam-Webster Dictionary defines marketing as "the activities that are involved in making people aware of a company's products, making sure that the products are available to be bought, etc." To make people aware of a library's products, the first step is to figure out the library's story. Start by asking staff this question: If they could use three words to describe the library, what would those words be? Reach out to power users and ask them how they feel about the library. Ask them what their neighbors who may be nonusers say about the library. All librarians have been asked at one point or another what they do and how they do it. The response used in those situations is a good place to start when considering the library's story. If the library has ever conducted a community assessment survey as part of developing a strategic plan, this can also be a good place to start when thinking about the library's story. How did the community view the library during the strategic planning process? Does the library want to tell a different story about itself?

Perhaps the library has recently undergone a major renovation and would like to be known as a local business center or coworking space in the community. Or it has just scheduled a lineup of continuing education classes and would like to be thought of as the go-to destination for lifelong learners. 


\section{AMPLIFY YOUR IMPACT}

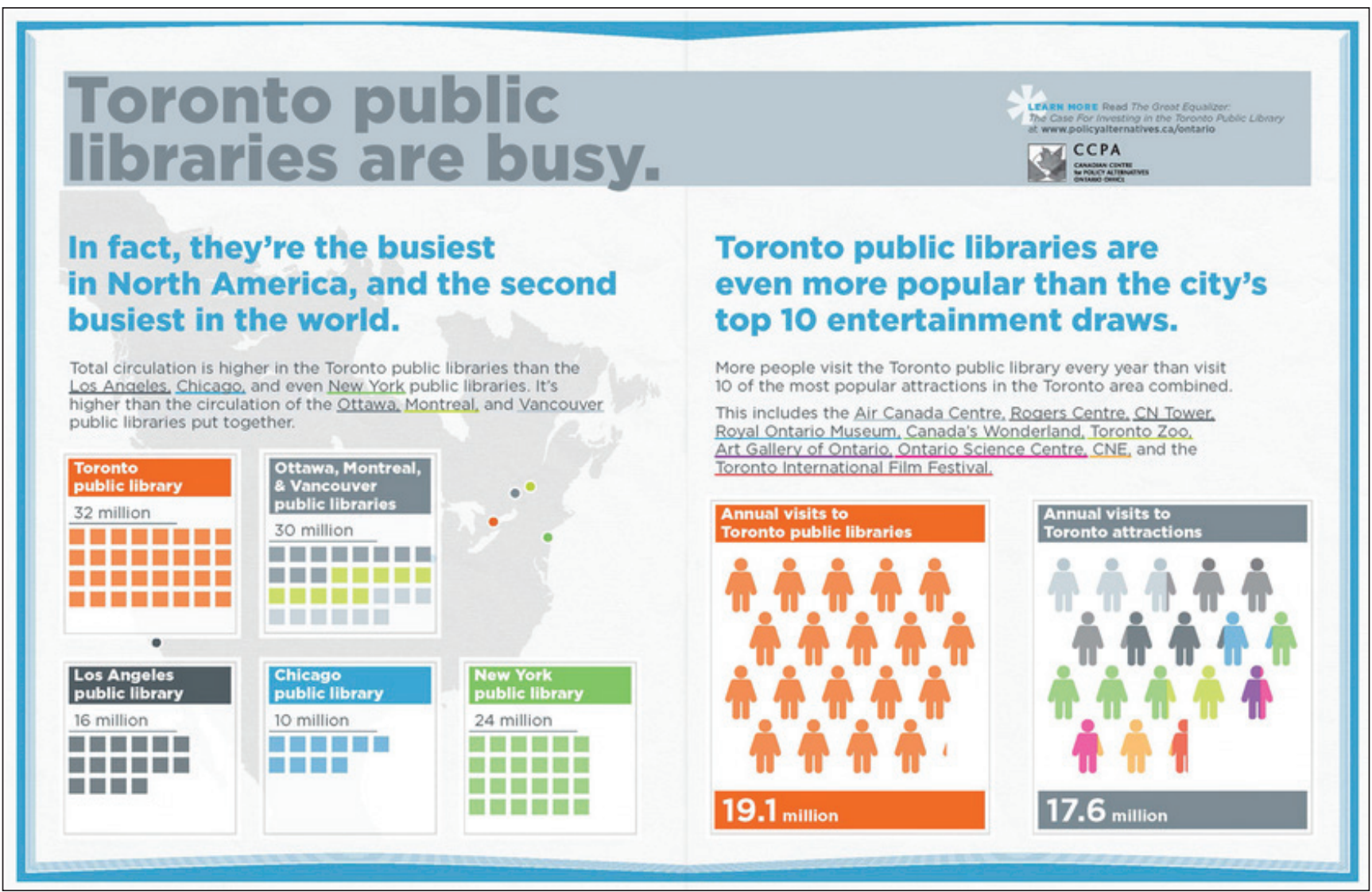

Figure 1. "Canadian Centre for Policy Alternatives" Screen captured from www.policyalternatives.ca/publications/facts-infographics/ infographic-how-much-do-torontonians-love-their-public-libraries.

Maybe it has recently focused on retraining staff in digital mediums and would like the community to view it as a kind of Apple Genius Bar for gadgets and devices. Whatever the library's story, figuring that out will be the first step in taking stock of marketing efforts to see if they are all telling that story in a cohesive manner.

Next, consider who in the community is telling the library's story. The physical and digital efforts the library puts out will be one thing, but consider who is using word-ofmouth. It's important to make sure information is disseminated in a way that puts everyone on the same page whether it be library staff, power users, board members, or citizen advisors. Several channels can be used to do this: meetings, email, annual appeal letters, a press conference, and infographics. The channel may be different for each group. For example, in a recent staff meeting, my colleagues and I were asked to separate into small groups and come up with a short elevator speech for when a user asks why he or she should support the library. It was a productive exercise in deciding what story we want to tell to community members who are not already library supporters.

After that, it's worth it to determine how to make it easier for those who are already telling the library's story to continue to do so. Each group will be different. For library staff, perhaps sharing one or two statistics or goals for the institution will be helpful as they can easily refer to those when the opportunity presents itself. For board members or citizen advisors who may be more familiar with what potential donors best respond to, it may be helpful to have different statistics or a list of goals that have already been accomplished and those that are still in progress. For power users who may want to engage nonusers with the library's story, an infographic can help. Figure 1 shows clearly and succinctly that Toronto public libraries are incredibly popular, and it was not even made by the library. It was made by a research institute interested in telling the library's story.

Next, take physical stock of the instruments used to tell the library's story. Collect press releases, flyers, posters, paid advertisements, swag, and any other physical objects that act as messengers within the community. Every single piece of physical marketing material should be, in some way, telling the library's story. For example, maybe the story is that the library is the new community center after merging with the cultural, senior, and recreational centers. Is there language that reflects this in the physical marketing material? Perhaps the library has a new logo, motto, or mission. It may seem tedious to put these items on all physical materials but this consistency will strengthen the message. 


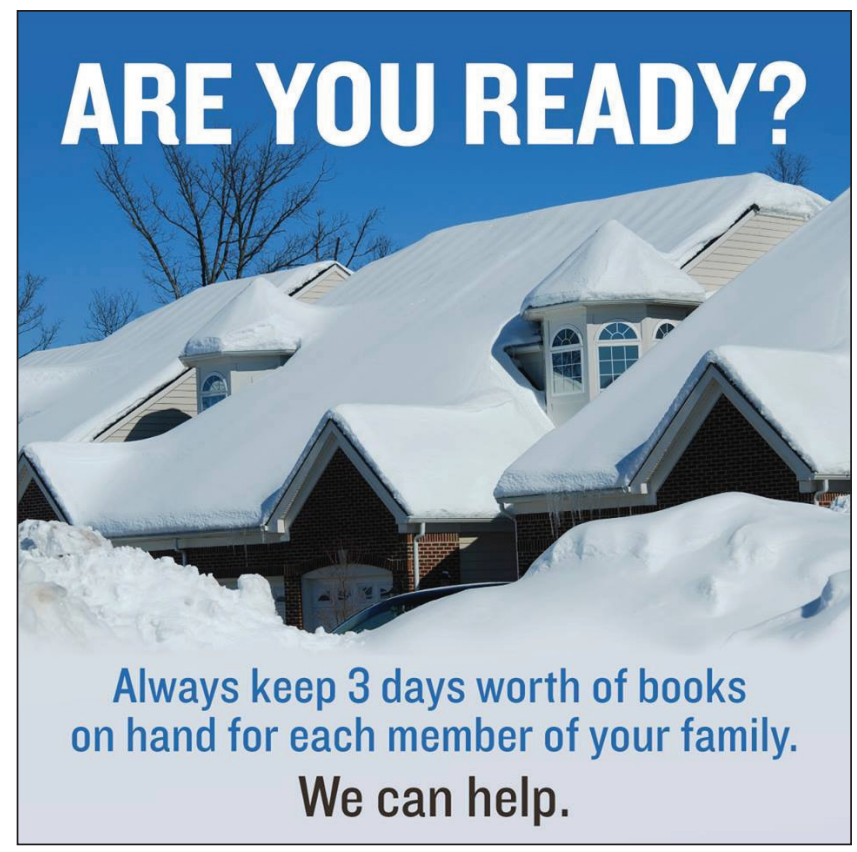

Figure 2. Just the Right Book's Facebook Page, accessed November 24, 2014, www.facebook.com/JustTheRightBook/ photos/a.210246155678253.46036.153926311310238/ 788174577885405.

Once the physical instruments have been examined, it's time to take a digital marketing inventory. Make a list of the social media channels where your library has a presence. Check in with the staff member(s) who work on each channel. Has engagement been increasing over time or has it remained stagnant? Since the digital world is ever changing, sometimes it's time to back out of a presence on a social media channel if your user base no longer flocks there. Conversely, maybe there are channels that have yet to be explored. Take a look at similar institutions that are doing well in these arenas and see if it's worth exploring for your library.

Check in with your email marketing campaigns. Look at how often e-blasts are sent out and which ones perform best. See if there is a trend in performance. Perhaps the emails sent in the middle of the day perform better than the ones sent in the evening. Every community is different, and I am often pleasantly surprised at how much our community enjoys receiving information about the library through email.

\section{AFTER THE INVENTORY}

Once you have conducted the marketing effort inventory, feel free to weed or develop just as one would a physical collection. To introduce your users to a never before told story about the library, an "out-of-the-box" marketing campaign to capture the attention of your community can work wonders, such as Dartmouth College's "Inspiring Ideas" campaign. They sought out individuals or groups who have drawn inspiration from the library and then encapsulated this on print and online materials. ${ }^{1}$ It ended up not only showing users what services the library can provide, but also introduced faculty and students to the work of their colleagues. This can be done on a much smaller scale as well, like putting the library's logo on some coasters for a book discussion that meets at the bar. ${ }^{2}$ The former example tells the story of the library as a place where inspiration is cultivated into academic work, and the latter tells the story of the library being a fun place to discuss intellectual pursuits in an informal setting. Both marketing campaigns work toward telling these libraries' stories. Take a look at campaigns that the library has launched in the past. Are your users still talking about it? If so, it may be worth trying again to promote something new and different.

Another example of an out-of-the-box marketing campaign, but this time with a missed opportunity, is this post on Just the Right Book's Facebook page (figure 2). This image had over 8,000 shares on Facebook and hundreds on Tumblr, but there is nothing embedded on the image that links it to the bookstore that created it. The image is visually interesting and evokes the same feeling one would get from a public safety awareness campaign. But there is no indication as to where the image came from, which is a missed opportunity for the creator.

Just as librarians regularly weed their collections, they should also regularly evaluate and weed their marketing efforts. This will help them avoid blending into the scenery of the information people receive on a daily basis. Not only that, it will help staff members be more efficient in sending their message to patrons, nonusers, advocates, and donors alike.

\section{References}

1. Andrea M. Bartelstein and Maryann Ryan, "Over the Counter Help," Reference and Users Services Quarterly 53, no. 2 (Winter 2013): 126-28.

2. Leah White, "Books On Tap: The Book Group that Meets in a Bar," Marketing Library Services 27, no. 5 (September/October 2013), accessed November 16, 2014, www.infotoday.com/mls/sep13/ White--Books-on-Tap--The-Book-Group-That-Meets-in-a-Bar .shtml. 